\title{
article
}

\section{Becoming primary caregivers? Unemployed fathers caring alone in Spain}

\author{
Concepción Castrillo, mccastrillo@ucm.es \\ Jesús Rogero-García, jesus.rogero@uam.es \\ Pedro Romero-Balsas, pedro.romero@uam.es \\ Gerardo Meil, gerardo.meil@uam.es \\ Universidad Autónoma de Madrid, Spain
}

This article analyses how unemployed fathers with employed partners broach childcare and how they conceive of their own identities. It aims primarily to determine whether these fathers actually play the part of primary caregivers. The analysis is based on in-depth interviews with 26 unemployed fathers who spent at least three months caring for their children. The findings show that these fathers engaged intensively in a wide variety of caring tasks. Nonetheless, their role as primary caregivers is called into question on the grounds of attitude. They tended to take for granted that they should set aside time and space for themselves, adding to their partners' dual workload. Moreover, the overall responsibility for care fell largely on mothers. Subjectively speaking, while one group of fathers resorted to egalitarian precepts to normalise their situation, for many others, the inability to meet the standard expectations of traditional masculinity prompted an identity conflict.

Key words childcare $\bullet$ fathering $\bullet$ unemployment $•$ masculinities $•$ primary caregiver

To cite this article: Castrillo, C. Rogero-García, J. Romero-Balsas, P. and Meil, G. (2020) Becoming primary caregivers? Unemployed fathers caring alone in Spain, Families, Relationships and Societies, vol 00, no 00, 1-16, DOI: 10.1332/204674320X15919852635855

\section{Introduction}

High unemployment, one of the major characteristics of the economic crisis that hit Spain in 2008, affected men more intensely than women during the recession. In 2015 when this research was conducted, 624,900 males between the ages of 30 and 39 were unemployed in Spain. Under those circumstances, as the number of households with an unemployed male and a woman with paid work rose significantly (Moreno Mínguez, 2015), many men began to care for their children alone on most working days.

The literature shows that although fathers who care for their children singlehandedly for a significant period of time become more engaged in child raising (Meil, 2013; O'Brien and Wall, 2017), that does not necessarily translate into an egalitarian distribution of such responsibilities. A need is felt, therefore, to analyse unemployed fathers' specific practices and subjective perceptions without unreflectingly assuming 